In Britain there is a specific reason why growth should continue for some years to come. The universities and similar institutions are at present turning out more than 20,000 qualified scientists each year, and it must be hoped that at least a quarter of these will find their way into research and development. Indeed, for some years to come, the annual increase of the labour force in research and development must be expected to grow by 7 or 8 per cent a year if the fullest value is to be derived from the expansion which the universitics have been asked to undertake. In other words, the annual cost of research and development should be expected to increase by some $f 60$ million even without the inflationary pressure of the steadily increasing cost of research and development of all kinds. Even if, as now seems likely, the G.N.P. does not change very much for some years to come, it would be folly to fail to make full use of the skilled manpower which has been expensively trained in recent years. There are ways of finding lower limits to what should be spent on research and developmentof suggesting how governments should make proper use of resources which exist already, or which will exist in the years immediately ahead. But what of the more distant future? How many qualified scientists and engineers will Britain need in the eighties? How much will have to be spent cach year if each is to work effectively ? There are no ready answers to questions like these, yet there is no sign that the trend towards increasing dependence on science and technology which has been the history of the past three decades will now quickly come to a halt. Indeed, things point mostly in the other direction. Tt will be a great surprise if the proportion of the G.N.P. being spent on research and development comes suddenly to a halt, in Britain or in the United States, in 1966. In the months between now and Christmas, when British government departments will be trying to decide how money should be spent in 1967-68, the Council for Scientific Policy will be saddled with the task of persuading the Treasury that growth is probably inescapable. The job would be far easier if the available statistics were more reliable. It will be impossible if there is too much dependence on fractions of the G.N.P.

\section{MALE AND FEMALE}

IT is naturally disappointing to read, on page 863 of this issue, that an interesting attempt to pre-determine the sex of cattle has not so far been successful. For some years now, work has been under way at the Institute of Animal Physiology of the Agricultural Research Council, and British farmers (as well as British newspapers) have been awaiting its outcome with the greatest intercst. They should not now be too downcast, for success at this stage may have been almost too much to hope for.

Dr. Keynes and his colleagues at Babraham have been following a lead provided by Dr. B. C. Bhatta- charya several years ago, in some experiments with rabbits. Then it seemed that if rabbit semen were cooled to $1^{\circ} \mathrm{C}$ to bring to a halt the movement of individual sperms, two distinct fractions would separate under the influence of gravity, that tending to sink more quickly tending to contain a predominance of sperms carrying the $X$ chromosomes which determine female offspring. The less dense fraction of the semen, on the other hand, would tend to contain a majority of $Y$ chromosomes and would, to that extent, produce buck rabbits when inseminated into fertile females. By all accounts it is extremely difficult to ensure that separation under gravity is not disturbed, which may be one explanation for the negative result of the experiment with cows at Babraham. But it may also be that such differences as exist between the sperms which carry $X$ and $Y$ chromosomes may not be significant in semen from bulls but just enough to make a perceptible difference in rabbits. More may be known about this when there has been a chance to improve on the statistical validity of the work with rabbits. In any event, however, progress is bound to be unsure until much more is known about the mechanism by which the supposed separation of sperms under gravity can be accomplished. The fact that $X$ chromosomes are larger and therefore heavier than $Y$ chromosomes is not a sufficient explanation, for the difference of density that would result is insufficient to explain the segregation which is observed. But may there not be physiological differences between sperms of the two kinds? This is what needs most urgently to be determined. Until much more is known about the ways, if any, in which the sex chromosomes can influence the macroscopic behaviour of the sperms which carry them, those who attempt to segregate fractions of semen will necessarily be working in the dark.

It does not follow, of course, that there can be no hope of determining the sex of cattle until all the more fundamental research has been successfully carried out. On the contrary, there is such a great economic benefit to be won from a way of making sure that dairy herds do not waste nearly half their breeding potential on unwanted bull calves that experiments are bound to continue, and deserve to be supported generously. But there are also other lines of enquiry to be followed. Talk of implanting fertilized ova of determined sex in fertile females is not entirely fanciful, even if there can be no assurance that methods which work with difficulty in the laboratory, and with laboratory animals, can be adapted to the trying circumstances of agriculture where, for example, surgical tcchniques are out of the question. Even if further developments should show that it is unreasonable to look for success, the comparatively modest cost of the work which needs doing would be an entirely prudent gamble. And fortunately there is no immediate prospect that it will be possible to apply any of these techniques to human beings, though it may not be too soon to ask how society should adapt itself to such a possibility. 